\title{
EL MAESTRO ORLANDO FALS BORDA SUS IDEAS EDUCATIVAS Y SOCIALES PARA EL CAMBIO EN LA SOCIEDAD COLOMBIANA
}

\author{
Dr. Javier Ocampo López ${ }^{1}$ \\ Universidad Pedagógica y Tecnológica de Colombia \\ Grupo de Investigación HISULA-SHELA \\ Javierocampo11@yahoo.es
}

Recepción: 2/06/2009

Evaluación: 3/06/2009

Aceptación: 10/06/2009

Artículo de Reflexión

\section{RESUMEN}

Este trabajo de investigación de HISULA en la serie de Educadores Latinoamericanos tiene por objeto el estudio de las ideas educativas y la metodología científica de la Investigación-Acción Participativa del educador Dr. Orlando Fals Borda, uno de los grandes ideólogos de la educación universitaria en Colombia. Se preocupa por el análisis de sus principales obras relacionadas con el estudio sociológico de los campesinos de los Andes y el Hombre y la Tierra en la región cundiboyacense del Altiplano Andino.

Este ilustre educador barranquillero hizo sus trabajos de investigación sociológica del pueblo colombiano y defendió el papel de la educación en el cambio social. Con su metodología de la investigación-acción participativa señaló los nuevos rumbos de la educación colombiana centrada en el alumno y en la filosofía del "aprender haciendo". En sus actividades docentes formó una generación de sociólogos dedicados a la investigación social en una época de crisis y de cambios. Por ello su acción se realizó en la Facultad de Sociología de la Universidad Nacional y en sus investigaciones científicas y educativas, destacando su metodología de "La investigación-Acción

\footnotetext{
${ }^{1}$ Doctor en Historia. Actualmente es profesor del Doctorado en Ciencias de la Educación de la Universidad Pedagógica y Tecnológica de Colombia - RUDECOLOMBIA, miembro del Grupo de investigación HISULA y de la Academia Boyacense de Historia.
} 
Participativa". Su actuación fue definitiva como ideólogo de la Constitución Nacional de 1991, en la cual se plasmaron algunas de sus ideas.

Palabras claves: Sociología, Investigación, Educación Popular, Universitaridad, Investigación Acción Participativa.

\title{
PROFESSOR ORLANDO FALS BORDA, HIS IDEAS SOCIAL AND EDUCATIONAL IDEAS FOR THE COLOMBIAN SOCIETY CHANGE
}

\author{
Dr. Javier Ocampo López \\ Universidad Pedagógica y Tecnológica de Colombia \\ HISULA-SHELA Research Group \\ Javierocampo11@yahoo.es
}

\begin{abstract}
This research work of HISULA, in the series of Latin American Educators, intends to study Professor Orlando Fals Borda's educational ideas as well as the action-research scientific methodology developed by him, one of the most outstanding ideologists of the university education in Colombia. Special emphasis is given on the analysis of his most known works related to a sociological study of the Andean peasants and the Man and the Earth in the Cundi-boyacense region at the Andean Highland. Born in Barranquilla, this illustrious educator had particular interest in developing Colombian people's sociological research and defending the education role in the social change. With his Action-Research methodology, he pointed out the Colombian education direction, in which students become their own learning protagonists through "learning by doing" philosophy. He trained a generation of noticeable sociologists, devoted to social research in a critical time of changes. Most of his work was carried out at the Sociology Faculty of Universidad National. It is to stand out his methodology of "Participatory Action-Research". His ideology influence was definitive and undeniable for the Constitución Nacional of 1991, which clearly kept in it some of his ideas.

Key words: Sociology, Education social university student, Faculty of Sociology, sociocultural Change. Peasants from the Andes. The Man and the Earth in Boyacá, Participatory Action-Research, Community action, Agrarian concern, Violence in Colombia, Subversion in Colombia, unconcluded Revolutions, Latin America and structural changes.
\end{abstract}




\section{INTRODUCCIÓN}

En la Historia de Educación colombiana existen grandes pedagogos de las Ciencias Sociales en la Universidad, cuyo pensamiento y acción fue de significativa importancia en la formación de las generaciones de la segunda mitad del siglo XX, y su proyección en el progreso y desarrollo de Colombia. Uno de ellos fue el eminente sociólogo y educador universitario Dr. Orlando Fals Borda (1925-2008), natural de Barranquilla, Profesor de la Universidad Nacional de Colombia y un gran investigador. Se destacó por sus estudios sociológicos, educativos, históricos, de cultura regional, de teoría y práctica social, investigación participativa y ordenamiento territorial. Sus obras "Campesinos de los Andes" (1955) y "El Hombre y la Tierra en Boyacá" (1957), publicadas en la Década de los Cincuenta del siglo XX, fueron decisivas para el conocimiento de la sociología y la psicología colectiva de nuestro pueblo andino de la meseta cundí-boyacense.

Esta investigación tiene por objeto el estudio del pensamiento y la acción del gran sociólogo y educador universitario colombiano Dr. Orlando Fals Borda, quien tuvo influencia decisiva en las ideas políticas, sociológicas y educativas en la segunda mitad del siglo XX, con proyecciones hacia el siglo XXI. Sus ideas metodológicas sobre la Investigación Acción Participativa han tenido influencia en los investigadores sociales y educativos con nuevas ideas para el cambio social en Colombia.

\section{La Facultad de Sociología en la Universidad Nacional}

Cuando después de sus estudios de postgrado a nivel de maestría y doctorado en Estados Unidos, regresó a Colombia, se interesó por la creación de la Facultad de Sociología en la Universidad Nacional de Colombia, la cual fundó en el año 1959, y en donde fue su Decano entre los años 1959 y 1967. Fue esta la primera Facultad de Sociología creada en América Latina. Su objetivo principal fue la formación de profesionales sociólogos con capacidad para realizar las investigaciones científicas sobre la realidad social colombiana. En la Facultad de Sociología, el Dr. Orlando Fals Borda fundó el primer postgrado de Maestría en Sociología de la Educación en Colombia, el PLEDES. Con el aporte de grandes científicos, entre ellos los doctores Germán Rama, Jorge Graciarena y Guillermo Briones, entre otros. Esta experiencia terminó en el año 1969; "varios estudiantes continuaron sus estudios en

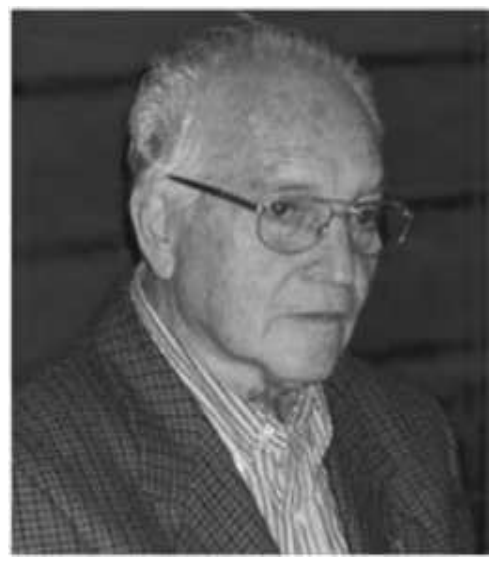

Dr. Orlando Fals Borda Universidades norteamericanas y europeas."

2 FALS BORDA, Orlando. (1965): "Nuevos rumbos y consignas para la Sociología”. En Conferencia en el aula máxima de la Facultad de Sociología el 28 de octubre.

\begin{tabular}{l|l} 
Rhela. Vol. 12. Año 2009, pp. $13-41$ \\
\hline &
\end{tabular}


El Dr. Orlando Fals Borda fue un educador de "grandes kilates". Según sus alumnos, fue un verdadero "Maestro universitario" con cuyas orientaciones formó una generación de investigadores en las Ciencias Sociales. "En sus primeras investigaciones en la Facultad de Sociología, su interés fueron los estudios de campo, con aplicación de encuestas, entrevistas, documentación de archivo, historia oral y otros aspectos de la investigación sociológica práctica y cuantitativa.”3

Los diversos problemas que afrontó la sociedad colombiana en las Décadas de los Cuarenta y los Cincuenta del siglo XX, que son los años de crisis y violencia, hicieron pensar, a muchos ideólogos como el Dr. Orlando Fals Borda, sobre la necesidad de un cambio en la sociedad colombiana. Se planteó la necesidad de una reforma social agraria, la justicia social, el movimiento de Acción Comunal y el desarrollo y progreso para el bienestar de la comunidad. Se habló de la coexistencia de dos sociedades diferentes: la arcaica rural y la moderna industrial.

Manifestándose la lucha entre la tradición y la modernidad y el enfrentamiento entre el Nacionalismo desarrollista y el Nacionalismo revolucionario. El desarrollista, con un cambio por evolución dentro de los partidos políticos tradicionales, liberal y conservador. Los partidos tradicionales buscaron la modernización o transformación nacional con reformas y evolución de las instituciones, estimulando amplios programas que rompían con lo tradicional. Así, lo plantearos e hicieron los gobiernos del Frente Nacional.

Por su parte, el nacionalismo revolucionario surgió como ideología de acción de los grupos que buscaron el cambio profundo y radical de la realidad político-social existente, hacia una nueva estructura política y social para Colombia. El Nacionalismo Revolucionario de los grupos de izquierda, partidarios del Estado Socialista, siguiendo las orientaciones de Cuba, la Unión Soviética, China y los países socialistas del Mundo. El Nacionalismo revolucionario cristiano se planteó alrededor de las ideas del Clero revolucionario que siguió las orientaciones de la Teología de la Liberación, destacando el pensamiento y la acción del cura Camilo Torres Restrepo, compañero del Dr. Orlando Fals Borda en la Facultad de Sociología de la Universidad Nacional; asimismo del Grupo Golconda, partidario del cambio revolucionario, "pensando en la justicia social, la ayuda a los menesterosos y el Catolicismo social."

El Padre Camilo Torres Restrepo fue uno de los Profesores de la Facultad de Sociología, quien con su pensamiento crítico analizó la realidad social de Colombia y se manifestó partidario del Nacionalismo revolucionario cristiano. Con sus ideas de cambio

\footnotetext{
3 FALS BORDA, Orlando. (1955): El método sociológico y el trabajo de campo. Facultad de Sociología de la Universidad Nacional. Lecturas Adicionales N 21 . Traducción por Álvaro Herrán Medina del Apéndice A del libro, Pessant Society in the Colombian Andes, publicada en 1955 por la Imprenta de la Universidad de Florida, Gainesville, E.U.A.

4 OCAMPO LÓPEZ, Javier. (1972): Las ideologías en la Historia Contemporánea de Colombia. México. Universidad Nacional Autónoma de México, Centro de Estudios Latinoamericanos, pp. 16-21.
} 
social para Colombia, conformó el movimiento político del Frente Unido. Sus ideas lo llevaron a un enfrentamiento con la Jerarquía Eclesiástica, que lo generó su vinculación con la guerrilla del ELN, y a su muerte, combatiendo en Patio Cemento (Santander) el 15 de febrero de 1966. "Este hecho político influyó en el Dr. Orlando Fals Borda, su decano y compañero de actividades docentes en la Universidad Nacional." 5

\section{Su Actividad Docente e Investigativa}

El sociólogo y humanista Orlando Fals Borda inició sus estudios universitarios en la Universidad de Dubuque, donde se graduó en Literatura inglesa e Historia en 1947. Posteriormente realizo sus estudios de Maestría en Sociología en la Universidad de Minnesota, donde el sociólogo y humanista Pitirim A. Sorokin había fundado la especialidad de Sociología rural. Sus estudios sociológicos los culminó en 1953, con su disertación magistral y tesis de grado "Campesinos de los Andes". Su Doctorado (Ph.D.) en Sociología Latinoamericana lo realizó en la Universidad de la Florida en 1955, bajo la dirección de Lynn Smith, antiguo alumno de Sorokin. Su disertación doctoral y tesis de grado fue "El Hombre y la Tierra en Boyacá". Lo anterior señala que en la formación del doctor Orlando Fals Borda, la Década de los Cincuenta fue básica para su fundamentación teórica

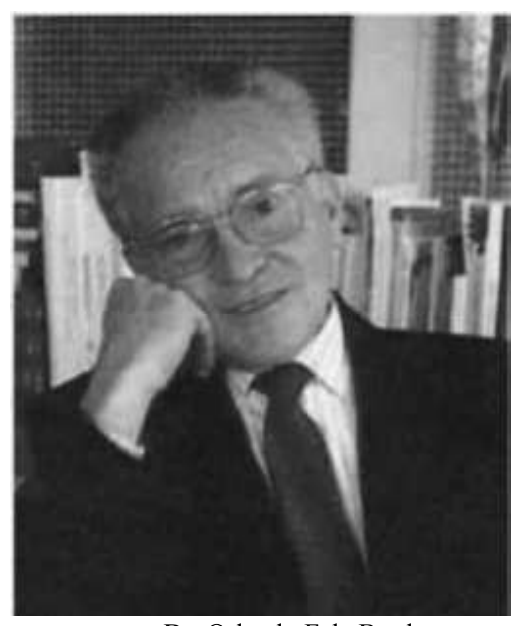

Dr. Orlando Fals Borda sociológica y educativa.

Con sus investigaciones en los estudios de Postgrado que presentó como tesis de grado, publicó sus dos obras más importantes en 1955 y en 1957. Su mayor interés fue el análisis del pueblo cundiboyacense de la Región Andina de Colombia, a través de la estructura socio-económica y las costumbres campesinas. Y en especial, el estudio del "Hombre y la Tierra en Boyacá", con una documentación relacionada con las bases sociológicas e históricas para una reforma agraria. "Esta publicación tuvo un hondo impacto en Boyacá, pues fue la primera obra científica realizada con una metodología sociológica e histórica, con significativa interpretación sobre el pueblo boyacense." ${ }^{6}$

Una vez culminados sus estudios en Estados Unidos, fue nombrado Consultor de la OEA en Brasil y luego Director General del Ministerio de Agricultura en Colombia. Sus principales programas los desarrolló alrededor del campesinado en Latinoamérica y especialmente en Colombia. Convirtiéndose en el científico social que más representó

\footnotetext{
5 Ibídem., pp. 22-38. TORRES RESTREPO, Camilo. (1967): Documentos politicos. México, Hora Cero, $\mathrm{N}^{\circ} 1$. Véase la obra de BRODERICK, Walter J. (1987): Camilo, el cura guerrillero. Bogotá, El Labrador. Asimismo, la obra de GUZMÁN CAMPOS, Germán. (1967): Camilo Torres, el cura guerrillero. Bogotá. Ediciones Especiales de la Prensa. PAREJA, Carlos H. (1968): El padre Camilo, el cura guerrillero. México, Editorial Nuestra América.

6 FALS BORDA, Orlando. (2006): El Hombre y la Tierra en Boyacá. Tunja, UPTC, Imprenta de la Universidad.
}

\begin{tabular}{l|l} 
Rhela. Vol. 12. Año 2009, pp. $13-41$ \\
\hline &
\end{tabular}


a Colombia a nivel internacional en Congresos sociológicos, foros, simposios y en publicaciones en diversas revistas internacionales. En sus actividades administrativas en el Ministerio de Agricultura se interesó por fortalecer el Programa de la Reforma Social Agraria, el INCORA y los programas de Directorios Veredales, Juntas de Vecinos y en especial las Juntas de Acción Comunal, de las cuales fue su ideólogo a nivel nacional.

El grupo académico que realizó el estudio sobre las causas de la Violencia en Colombia, recomendó la creación de las Juntas de Acción Comunal en todo el territorio Nacional. La Acción Comunal se convirtió un una política estatal del Presidente Alberto Lleras Camargo, comenzando desde un principio con el auspicio institucional. Se inició en los epicentros de la violencia en las zonas rurales de Caldas, Huila, Tolima, Santanderes, Valle y Nariño para luego extenderse paulatinamente a otras áreas rurales y barrios marginados de las grandes ciudades y finalmente al resto del territorio nacional.

Las Juntas de Acción Comunal fueron creadas oficialmente mediante la Ley 19 de 1958 y reglamentadas mediante el Decreto 1761 de 1959. Se dispuso la creación de la División de Acción Comunal, adscrita inicialmente al Ministerio de Educación, y un año después al Ministerio de Gobierno. El Dr. Orlando Fals Borda se convirtió en uno de los ideólogos y adalides en Colombia de las "Juntas de Acción Comunal, que se organizaron en las veredas del mundo rural colombiano y en los barrios de las ciudades colombianas."

En la Década de los Setenta, Orlando Fals Borda se interesó por realizar estudios con el método de investigación acción participativa, que buscaba la investigación sociológica en las culturas populares, conocer sus necesidades sociales y promocionar una conciencia social para transformar la realidad con base en las necesidades sociales en los grupos más necesitados de la población. Estas investigaciones sociológicas las promovió a través de la Fundación "La Rosca", de la cual fue director entre los años 1970 y 1975. Del mismo modo en esa Década fundó la Editorial "Punta de Lanza" y la revista "Alternativa" en la Década de los Setenta, la cual volvió a editar en los años Noventa."Su interés fue la educación popular, los problemas agrarios y la crítica al reformismo y el cooperativismo."

Con el método de investigación activa, el Dr. Fals Borda realizó su libro "Historia de la cuestión agraria en Colombia", publicado en 1975, cuyos datos y análisis fueron discutidos con campesinos e intelectuales de diversas regiones del país. En sus contactos directos con los campesinos de Córdoba y de otras regiones de la Costa Atlántica preparó su obra Historia doble de la Costa, de investigación Acción Participativa, que realizó

\footnotetext{
7 FALS BORDA, Orlando. (1961): Acción comunal en una vereda colombiana. Bogotá, Facultad de Sociología, Universidad Nacional. Monografía $N^{\circ} 4$.

8 FALS BORDA, Orlando. (1992): La ciencia y el pueblo, nuevas reflexiones. En la obra Investigación-Acción Participativa. Bogotá, Editorial Magisterio, pp. 65-84. Véase el estudio de PARK, Peter Qué es la investigación-acción participativa. Perspectivas teóricas y metodológicas. En la obra Investigación-Acción Participativa. Op., cit. pp. 135-174.
} 
entre los años 1979-1986 y que publicó en cuatro tomos. "En esta obra estudió las luchas populares de la Costa Atlántica Colombiana, desde la conquista hasta finales del siglo XX."

En la Década de los Ochenta fue organizador de Colombia Unida y participó en la Alianza Democrática M-19. En el año 1985 fundó el Instituto de Estudios Políticos y Relaciones Internacionales en la Universidad Nacional, en donde continuó en la investigación científica como "Profesor emérito".

En la Década de los Noventa del siglo XX, su mayor interés fue la regionalización colombiana, con la cual propuso el reordenamiento territorial de Colombia, que fue debatido en la Asamblea Nacional Constituyente en 1991, en la cual fue constituyente y uno de los ideólogos de la Constitución Nacional de 1991. Por sus méritos recibió la Gran Cruz de Boyacá, los premios Guggenheim, Kreisky y Hoffman; y hasta sus últimos días fue un incansable impulsor de movimientos y reformas populares. En la última década del siglo XX y en la primera del siglo XXI se dedicó a la revolución democrática $\mathrm{y}$ al reordenamiento territorial de Colombia.

Para la realización de sus investigaciones y actividades, conformó el Centro Estratégico de Pensamiento Alternativo, del cual fue Presidente desde su fundación hasta su muerte. En sus últimos años fue uno de los ideólogos políticos y sociales del Polo Democrático Alternativo, del cual fue Presidente honorario. "En octubre del año 2002, la Universidad Pedagógica y Tecnológica de Colombia le otorgó el título de Doctor Honoris Causa y le hizo la reedición de su obra "El Hombre y la Tierra en Boyacá". Asimismo, editó la obra de su esposa la Doctora María Cristina Salazar, Los esclavos invisibles: Autoritarismo, explotación y derechos de los niños en América Latina. El Dr. Orlando Fals Borda falleció en Bogotá a los 83 años, el 12 de agosto de 2008." 10

En la temática social, el Dr. Orlando Fals Borda se interesó por el cambio social y por los problemas de la subversión en Colombia; además, aplicó la "sociología comprometida" con los estudios sobre los movimientos campesinos, sindicales y estudiantiles. Junto con el sacerdote revolucionario Camilo Torres Restrepo, desde el Frente Unido en los años 1964 y 1965, promovió un movimiento de izquierda pensando en el cambio social para Colombia.

\footnotetext{
9 FALS BORDA, Orlando. (1975):_Historia de la cuestión agraria en Colombia. Bogotá, Punta de Lanza, _.(1979): Historia Doble de la Costa. Mompox y Loba. Bogotá, Carlos Valencia Editores. Tomo I. El Presidente Nieto. (1981): Tomo II; Resistencia en el San Jorge. (1984): Tomo III. Retorno a la tierra. (1986), Tomo IV. Edición especial de la Vicepresidencia de la República, Bogotá, Ancora Editores, 2002. (4 tomos).

${ }^{10} \mathrm{La}$ obra publicada por la UPTC de Tunja, como un homenaje al Dr. Orlando Fals Borda, a quien se le otorgó el título de Doctor Honoris Causa: El Hombre y la Tierra en Boyacá. Bases sociológicas e históricas para una Reforma Agraria. Tunja. UPTC. Universidad Pedagógica y Tecnológica de Colombia, 2006. Asimismo, la obra de su esposa SALAZAR, María Cristina. (2006): Los esclavos invisibles. Autoritarismo, explotación y derechos de los niños en América Latina. Tunja, UPTC.
} 


\section{Sus Estudios sobre el Mundo Campesino de la Región Andina y la Costa Atlántica Colombiana}

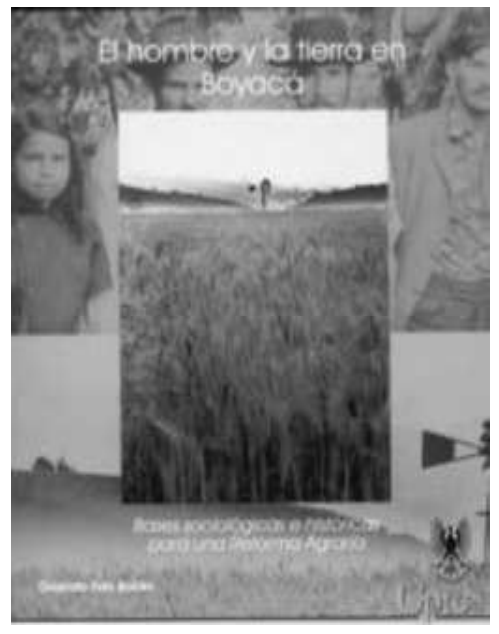

Sus estudios de investigación sociológica, sobre el Mundo campesino fueron numerosos, destacando entre ellos los siguientes: "Campesinos de los Andes" (1955);"El Hombre y la Tierra en Boyacá: Bases sociológicas e históricas para una Reforma Agraria" (1957); "Historia de la cuestión agraria en Colombia" (1975); "La teoría y la realidad del cambio sociocultural en Colombia" (Bogotá, Universidad Nacional). Otros estudios sobre el Mundo rural: "La vereda de Chambimbal: estudio y acción en vivienda rural" (1958), "Acción comunal en una vereda colombiana (1961); "La comunicación de las ideas entre los campesinos colombianos" (1962); "La esencia de la transformación rural. Estudio de una comunidad rural" 1965); "Notas sobre el vestido campesino en la Colombia Central", "Los orígenes del problema de la tierra en ChocontáColombia", "Estratos sociales entre los campesinos colombianos", "El campesino cundiboyacense: conceptos sobre su pasividad", "Aspectos psicosociológicos de la vivienda rural colombiana", "Sentido político del Movimiento campesino en Colombia". Su investigación "Campesinos de los Andes", es un estudio sociológico sobre el campesinado tradicional en Saucío, una vereda del municipio de Chocontá en Cundinamarca. Allí estuvo compartiendo con los campesinos en los mediados del siglo XX, entre los años 1949 y 1951. Presenció la pasividad y atraso del campesino tradicional en Saucío, pero también, el proceso de cambio con la modernización de la región.

Esta obra que fue la tesis de grado para su Maestría en Sociología en la Universidad de Minnesota (USA), fue editada inicialmente en inglés en la Universidad de la Florida, Gainesville, en el año 1955. Bajo el titulo: "Peasant society in the Colombian Andes: a sociological study of the Saucio". Su maestro, el sociólogo Dr. T. Lynn Smith, la consideró como una obra modelo para el conocimiento de los campesinos de los Andes en Suramérica. Posteriormente fue publicada en español en la Universidad Nacional en el N 7 de las Monografías Sociológicas de la Facultad de Sociología en el año 1961. En ella se estudian los aspectos sociales de la dinámica social y con ella los principios causales de los cambios socioculturales en el medio rural colombiano.

En esta investigación se resalta la condición rural en Colombia, a pesar del avance en la industrialización y la modernidad de las principales ciudades colombianas. En los mediados del siglo XX, la mayor parte de las gentes vivían en los campos, dedicados a la agricultura y aún no se había presentado el problema de la emigración de los campesinos a las ciudades, como ocurrió en la segunda mitad del siglo XX. Por ello, el aporte del sociólogo Fals Borda es el análisis de la sociedad campesina de la comunidad andina de Saucio, con caracteres de pasividad, resignación y con resistencia al cambio. Sin embargo, la construcción de una represa y el mejoramiento de la carretera, señalaron 
la gran posibilidad del cambio en esta vereda de estructura tradicional. La organización social en la vereda de Saucío, la morfología del vecindario, la población, el hombre y la tierra, la evolución del poblamiento, las características de la agricultura intensiva, la minería del carbón y otros aspectos del trabajo como la fabricación de ladrillos y la construcción de casas. Se analiza el nivel de vida en la vereda de Saucío; la estratificación y posición social y las instituciones sociales.

Una tercera parte de la obra está relacionada con la cultura y la personalidad: la formación del campesino, la función de la religión en la vida campesina, el ethos de Saucío: la Semana Santa, las devociones a los santos, las costumbres de la cruz de mayo y la palma bendita y varias escenas del acaecer cotidiano. Son interesantes los estudios sobre el lenguaje campesino, su música y bailes, sus coplas, sus creencias populares, sus agüeros y supersticiones. Estudia también los trajes típicos campesinos, la vivienda campesina, la escuela de la vereda, la agricultura y sus técnicas, el mercado y otros aspectos de su vida cotidiana.

El Dr. Orlando Fals Borda estudió la pasividad de los campesinos de los Andes, pero también su potencialidad, su creatividad y talento, propicios para recibir los cambios de vida. En los mediados del siglo XX, se manifestó en Saucío un proceso de cambio de la tradición a la modernidad. Aun cuando el problema fue su profunda raigambre en la tradición de muchos siglos de permanencia, las nuevas formas de vida propiciaron otros lineamientos hacia la modernización. "Este es el aporte significativo de la obra "Campesinos de los Andes" del sociólogo Orlando Fals Borda."

Su estudio sobre "El Hombre y la Tierra en Boyacá. Bases sociológicas e históricas para una Reforma Agraria", es un aporte científico-social para el análisis de la sociedad rural de Boyacá en los mediados del siglo XX. Es trabajo de investigación del sociólogohistoriador Dr. Orlando Fals Borda, obtenido en fuentes directas documentales del Archivo Nacional de Colombia, Sala Colonia, Resguardos de Boyacá; Archivo histórico de Tunja; Archivos de las Notarías Primera y Segunda de Tunja, Notaría de Turmequé, Archivo del Catastro Departamental de 1954 y otros Archivos y manuscritos relacionados con el campesinado boyacense en los mediados del siglo XX.

Esta obra es considerada como uno de los grandes estudios históricos, con fuentes documentales primarias y con historia cuantitativa sobre el Hombre y la tierra en Boyacá. Asimismo, es una investigación sociológica, antropológica y demográfica sobre Boyacá, desde la época colonial hasta la primera mitad del siglo XX. Fue sustentada como tesis doctoral en la Universidad de la Florida en Gainesville, en el año 1955 y publicada en el año 1957. Destacamos sus estudios sobre el pasado histórico del pueblo boyacense, las formas de poblamiento, la demografía histórica de Boyacá, la tenencia de la tierra, los sistemas de división y titulación de la tierra, el tamaño de la propiedad, los sistemas

11 FALS BORDA, Orlando. (1961): Campesinos de los Andes. Estudio sociológico de Saucio. Bogotá. Universidad Nacional, Facultad de Sociología, Monografías sociológicas $\mathrm{N}^{\circ} 7$. Editorial Iqueima. 
agropecuarios, la estructura de los grupos ecológicos, la conducta y política como reflejo de lo agrario.

Con una metodología sociológica rigurosa, el Dr. Orlando Fals Borda se dedicó a investigar los fenómenos sociales en la región rural del Departamento de Boyacá, que es representativa de otras en Colombia y en general de América Latina. Aplicó el método científico al estudio directo de aquellas relaciones entre el hombre y la tierra que han sido institucionalizadas por el grupo colombiano que se encuentra en el Departamento de Boyacá. Como bien expresa en su introducción:

He tratado de describir la naturaleza de las relaciones entre el boyacense y su tierra como se observan hoy; pero también he estudiado la historia de estas instituciones y la naturaleza de los cambios que han sufrido desde el tiempo de los indígenas y cuando los españoles colonizaron la región. ${ }^{12}$

En su estudio profundo sobre Boyacá en los mediados del siglo XX, se manifiesta una transición entre la sociedad boyacense tradicional y la sociedad moderna. Este proceso socio-económico se manifestó en el Gobierno del Presidente Gustavo Rojas Pinilla, boyacense, quien fortaleció la Siderúrgica Paz de Río, la Electrificadora de Boyacá, la pavimentación de la carretera de Bogotá hasta Sogamoso, los programas de Acción Cultural Popular, la fundación de la Universidad Pedagógica de Colombia en Tunja y cuando el optimismo se generalizó, para el fortalecimiento del Corredor Industrial en Boyacá. Sin embargo, el estudio sobre el mundo rural boyacense que hizo el sociólogo Fals Borda, señala la realidad de un pueblo con profundas tradiciones y problemas propios de una sociedad minifundista, profundamente religiosa y grandes fanatismos políticos que se reflejaron en los años de la violencia. En sus estudios recalcó que el problema de Boyacá como en general en Colombia es la estructura agraria colonial que se estableció desde el siglo XVII y que necesita con urgencia la Reforma social agraria, sin la cual no será posible la justicia social y la paz en Colombia.

La obra "El Hombre y la Tierra en Boyacá. Bases sociológicas e históricas para una Reforma Agraria, refleja una radiografía de la sociedad rural en el Departamento de Boyacá, que es la misma del problema rural colombiano y latinoamericano. Se interesa por el estudio de los problemas rurales de Boyacá: las relaciones de propiedad y el uso de la tierra, los problemas del minifundio en Boyacá, la parcelación de las haciendas, los conflictos tradicionales entre las familias y las veredas y en general, los problemas de la tierra en Boyacá. Son de importancia sus estudios sobre las "Visitas" en la época colonial y las transformaciones de la tierra en la época republicana, especialmente la fragmentación de la propiedad y los problemas de la "minifundización". "Estudia los diversos temas agrarios y los proyecta a través de la historia, desde la producción agraria chibcha hasta les mediados del siglo XX. Es uno de los trabajos de investigación que más ha tenido repercusión para el análisis socio-económico del pueblo boyacense."13

12 FALS BORDA, Orlando. (2006): El Hombre y la tierra en Boyacá., Op. cit. p.30

13 Ibídem, p.45 
- Aspectos históricos de la Costa Atlántica: Un interés en sus estudios fue el análisis de la Costa Atlántica Colombiana, su región natal costeña, destacando la obra Historia doble de la Costa, escrita en cuatro tomos: "Mongós y la Loba, Tomo I, (1979); "El Presidente Nieto, Tomo II, (1981); "Resistencia en el San Jorge, Tomo III (1984); "Retorno a la tierra, Tomo IV, (1986). "Esta obra, escrita durante siete años, es considerada como una de las más importantes de la Costa Atlántica en la segunda mitad del siglo XX. Se interesa por estudiar la Historia de la Costa Atlántica desde los sectores inferiores, los más olvidados de la Historia." 14

Para la investigación de "Historia doble de la Costa" aplicó el Método de Investigación Acción Participativa (IAP). Según sus ideas, señala que trabajando y aprendiendo en acciones de tipo colectivo se logra una mejor posibilidad de transformación de una determinada situación. Sobre la Costa Atlántica destacamos también su trabajo de investigación "Capitalismo, hacienda y doblamiento en la Costa Atlántica”, publicado en el año 1976.

\section{Sus Estudios sobre la Violencia y la Subversión en Colombia}

Con Monseñor Germán Guzmán Campos y Eduardo Umaña Luna publicó en 1963 en la Colección de "Monografías sociológicas" la obra "La Violencia en Colombia", que es reconocida como el estudio social que más impacto tuvo en la sociedad colombiana en el siglo XX. Es el análisis del problema colombiano de las Décadas de los Cuarenta y los Cincuenta que ocasionó más de 300.000 muertes por problemas de fanatismo político, bandidaje, delincuencia y demás aspectos que inundaron de tragedia y desolación al pueblo colombiano.

Los miembros de la Comisión Investigadora de las Causas Actuales de la Violencia en Colombia, organizada por la Junta Militar de Gobierno fueron los siguientes: el Dr. Otto Morales Benítez, Absalón Fernández de Soto, Augusto Ramírez Moreno, los generales Ernesto Caicedo López y Hernando Mora Angueira, Monseñor Germán Guzmán Campos y el sacerdote Fabio Martínez; además, representantes del Ejército, del clero, militares retirados y de los dos partidos políticos tradicionales. Ellos realizaron esta investigación que tuvo honda repercusión en Colombia. Su misión fue tomar contacto con todas las personas o grupos alzados en armas; visitar las regiones en las cuales existía violencia o se padeció en alguna época y, proponer medidas al gobierno para solucionar los graves interrogantes humanos, económicos y de desajuste de la vida civil.

Una proyección de la Comisión Investigadora de las Causas de la Violencia en Colombia fue la obra "La Violencia en Colombia", escrita por Monseñor Germán Guzmán Campos, con capítulos interpretativos de los doctores Orlando Fals Borda y Eduardo Umaña Luna. Esta obra fue publicada en la Colección "Monografías

14 FALS BORDA, Orlando. Historia Doble de la Costa, Op., cit. p.50

Rhela. Vol. 12. Año 2009, pp. 13 - 41 
sociológicas" $\mathrm{N}^{\mathrm{o}} 12$, de la Facultad de Sociología de la Universidad Nacional de Colombia. Su primera edición fue en junio de 1962 y la segunda edición, en septiembre del mismo año. En el prólogo que hizo el Decano Dr. Orlando Fals Borda, inicia su disertación con una frase del Evangelio: "Cada árbol por su fruto se conoce; que ni de los espinos se cogen higos, ni de la zarza se cosecha uva". Así expresó en el prólogo el Decano de Sociología:

Para la sociedad colombiana, el problema de la "violencia" es un hecho protuberante. Muchos lo consideran como el más grave peligro que haya corrido la nacionalidad. Es algo que no puede ignorarse, porque irrumpió con machetes y genocidios, bajo la égida de guerrilleros con sonoros sobrenombres, en la historia que aprenderán nuestros hijos; porque su huella será indeleble en la memoria de los sobrevivientes y sus efectos tangibles en la estructuración, conducta e imagen del pueblo de Colombia. Por lo mismo, un problema social de tal magnitud no podía ser ignorado por la Facultad de Sociología, creada en el mismo lugar de los hechos. ${ }^{15}$

La obra "La Violencia en Colombia" presenta los aportes de la investigación que hizo Monseñor Germán Guzmán Campos con la Comisión investigadora de las causas de la Violencia en Colombia. Monseñor Guzmán Campos recibió el permiso del Obispo de la Diócesis de Ibagué Monseñor Rubén Isaza Restrepo, para cooperar con los estudios de la Violencia en Colombia, por solicitud del Señor Presidente de la República Alberto Lleras Camargo. La obra se realizó en tres partes: la primera está relacionada con la Historia y la Geografía de la Violencia: sus antecedentes históricos, la primera ola de Violencia, la segunda ola de Violencia y la Geografía de la Violencia en Colombia. La segunda parte se relaciona con los elementos estructurales del conflicto: los grupos en conflictos, semblanza de los Jefes guerrilleros, tácticas y normas de los grupos en armas, manifestaciones culturales de los grupos en conflicto, anatomía en Colombia y la quiebra de las instituciones fundamentales.

La tercera parte de la obra se relaciona con la Sociología de la Violencia, con interpretaciones sociológicas y jurídicas de los investigadores Orlando Fals Borda y Eduardo Umaña Luna. Incluye los estudios sobre algunas consecuencias de la violencia, los factores socio-jurídicos de la impunidad, capítulo escrito por el jurista Eduardo Umaña Luna; y por último, la interpretación sociológica que hizo el Dr. Orlando Fals Borda sobre el conflicto, la violencia y la estructura social colombiana. Profundiza en la estructura y función en el marco de la violencia, la teoría del conflicto, la teoría de los valores y el agrietamiento estructural.

"El Dr. Orlando Fals Borda interpretó la violencia como un proceso dentro del contexto teórico del conflicto social, con múltiples facetas y formas de análisis con

15 Monseñor GUZMÁN CAMPOS, Germán, FALS BORDA, Orlando y UMAÑA LUNA, Eduardo. (1962): La Violencia en Colombia. Estudio de un proceso social. Bogotá, Ediciones Tercer Mundo. Facultad de Sociología Universidad Nacional. Monografías sociológicas, $\mathrm{N}^{\circ}$ 12. Prólogo del Dr. Orlando Fals Borda, Decano de la Facultad de Sociología, pp. 11-18. 
diversas teorías para su explicación; una de ellas, es la teoría estructuralista para el conocimiento de lo acaecido en Colombia con el agrietamiento estructural." ${ }^{16}$

Su obra "La subversión en Colombia: visión del cambio social en la Historia" fue editada en el año 1967 y su segunda edición en 1968. Su última edición actualizada, fue publicada por la Editorial FICA y el Centro Estratégico de Pensamiento Alternativo CEPA, 2008 (Última obra reeditada, antes de su muerte). El objetivo inicial de esta obra fue el estudio de las sucesivas frustraciones del destino histórico del pueblo colombiano, y el papel que en ellas han jugado las sucesivas generaciones.

Este libro fue hecho en memoria del Padre Camilo Torres Restrepo, después de su muerte en febrero de 1966. En él se destaca su influencia intelectual y personal en el pueblo colombiano y en el mundo latinoamericano. En esta obra, el sociólogo Fals Borda se interesa por el estudio de la Subversión en Colombia: sus fines e ideales. Analiza los problemas que surgen ante la descomposición del Orden. Y en una visión histórica de Colombia, además, estudia: el orden social de los chibchas; la formación del orden señorial en la época colonial; la subversión y frustración en el siglo XIX en Colombia; el ajuste y compulsión del orden burgués; la subversión y frustración en el siglo XX; el orden del Frente Nacional; la reiteración de la utopía; alternativas para la proyección; una galería de héroes subversivos en Colombia y un resumen sobre el cambio social en la Historia de Colombia desde 1493 hasta 1968. "Es una obra de interpretación hermenéutica sobre la Subversión en la Historia de Colombia."17

\section{Sus Estudios sobre América Latina y otros Temas de Investigación}

El sociólogo Fals Borda se interesó por el desenvolvimiento histórico de América Latina y por su transformación económica y social en la segunda mitad del siglo XX. En su obra Las Revoluciones inconclusas en América Latina (1809-1968) se interesa por analizar la subversión en América Latina y su importancia histórica. Asimismo, estudia el cambio marginal y su aplicación a la Guerra de Liberación en el período histórico entre los años 1809 y 1830: el cambio marginal en los valores; el cambio marginal en las normas y en la organización social: el cambio marginal en la tecnología y la marginalidad en perspectiva.

En las Revoluciones inconclusas en América Latina se preocupa por el estudio de la antiélite y su papel en el cambio social. Un caso de captación reaccionaria (18481854); un caso de captación positiva, pero inconclusa (1822-1948) y la búsqueda de nuevas antiélites. Estudia el sentido actual de los movimientos guerrilleros; su estrategia y tácticas; liderazgo y composición; tendencias actuales; y el reto moral de las guerrillas. Termina su obra con un estudio general sobre las Revoluciones inconclusas en América

\footnotetext{
16 Ibídem., pp. 287-420.

17 FALS BORDA, Orlando. (1968): Subversión y cambio social. Bogotá, Tercer Mundo, Colección "Dedo en la Herida", N ${ }^{\circ} 29.4^{a}$ edición actualizada, La Subversión en Colombia. El cambio social en la Historia. Bogotá, FICA y CEPA (Centro Estratégico de Pensamiento Alternativo), Noviembre 2008.
} 
Latina: frustración de los procesos sociales; fallas en campañas socioeconómicas; factores negativos de grupo y personalidad. Es el análisis del entonces Director de Programas en el Instituto de Investigaciones para el desarrollo en las Naciones Unidas en Ginebra. "Estas conferencias fueron expuestas por el sociólogo Orlando Fals Borda en la Universidad de Londres y en las Universidades de Oxford y Essex." 18

Otros trabajos de investigación sobre América Latina fueron publicados por la Facultad de Sociología de la Universidad Nacional y por otras instituciones nacionales e internacionales, destacando entre los siguientes: La transformación de América Latina y sus implicaciones sociales y económicas" (1961); "El Brasil: Campesinos y Vivienda" (1963); "Subversión y desarrollo: el caso de América Latina" (1970). "El Reformismo por dentro en América Latina". (1972). "Conocimiento y Poder popular, lecciones con campesinos de Nicaragua, México y Colombia” (1986)

- Sobre la Región: "Región y Cultura: algunas implicaciones teóricas y políticas" (1990); "Región e Historia. Elementos sobre ordenamiento y equilibrio regional en Colombia", (1996). "Acción y espacio: autonomías en la nueva república" (2000), "Kaziyadu. Registro del reciente despertar territorial en Colombia", "Reconocimiento y construcción del Magdalena Medio como entidad territorial emergente" (1996). "El territorio como construcción social" (1998), "Visión del ordenamiento territorial colombiano en el siglo XX" (Nueva Historia de Colombia, 1998).

-Sobre el Socialismo: "El socialismo que queremos: Un pacto social y político en Colombia" (1982); "Democracia y participación: algunas reflexiones" (1987), "Ante la crisis del país” (2003); “¿Por qué el socialismo ahora? (2003).

- Sobre aspectos historiográficos. "Fray Pedro de Aguado, el cronista olvidado de Colombia y Venezuela", Cali, Editorial Franciscana de Colombia, 1956. "La superación del eurocentrismo" (2002).

En algunas de sus obras y artículos, el sociólogo Orlando Fals Borda se interesó por el estudio comparativo de Colombia con América Latina; y el análisis de los diversos problemas que reflejan la estructura social, económica, política, cultural y educativa de estos pueblos en proceso de cambio, en búsqueda permanente por llegar a la meta del progreso, el adelanto y la paz en la armonía y justicia social.

\section{Sus Estudios sobre la Educación y la Ciencia en Colombia.}

El Dr. Orlando Fals Borda realizó algunos estudios sobre la educación colombiana, mencionando entre ellos: "La educación en Colombia: Bases para una interpretación sociológica" (1962). "La educación en el proceso revolucionario", en la obra "Por ahi es la cosa: educación en Colombia". (1971). "Aspectos críticos de la cultura colombiana: 1886-1986) (Revista Foro, (1987) y otros.

18 FALS BORDA, Orlando. (1968): Revoluciones inconclusas en América Latina 1809-

1968. México, Siglo XXI Editores. 


\section{La Necesiad de una Ciencia Propia ante el Colonialismo Intelectual}

Una de sus grandes preocupaciones fue la investigación sobre la educación y las Ciencias Sociales en los países del Tercer Mundo, ante las dificultades económicas y las influencias de las grandes potencias en los métodos y formas de la investigación científica. Según sus ideas, en Colombia y en general en Latinoamérica existe un colonialismo intelectual, que necesita un cambio para llegar a alcanzar una ciencia propia para los latinoamericanos. Necesitamos que los investigadores piensen en los estudios sobre Colombia y en general sobre América Latina con criterios científicos propios aplicados a nuestra realidad, que son diferentes a las realidades de Europa, Estados Unidos y el Mundo.

En su estudio "Ciencia propia y colonialismo intelectual" que presentó en la Facultad de Sociología en diciembre de 1968, considera que los científicos sociales de América Latina

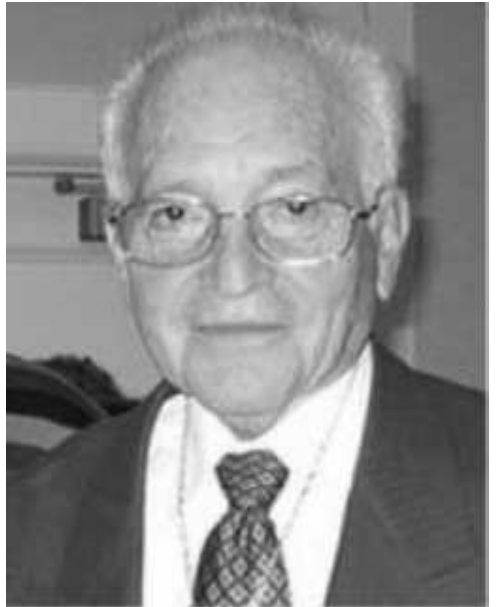

Dr. Orlando Fals Borda deben fortalecer la investigación autónoma e independiente de los hechos sociales, estimulando el pensamiento creador y la originalidad. Esto es indispensable, porque las realidades encontradas son de un tipo conflictivo y diacrónico sobre el cual se conoce muy poco en los países avanzados de donde se difunden las pautas científicas. Las metodologías y orientaciones ofrecidas en estos países pueden ser parcialmente contraproducentes. "En cambio, la observación directa y la intervención personal en los procesos del cambio profundo, muchas veces revolucionarios -tan característicos de las regiones en desarrollo-, pueden derivarse las más valiosas contribuciones al conocimiento sociológico, siempre y cuando se trabaje en ello con seriedad y disciplina." ${ }^{19}$

En su conferencia sobre el tema "Nuevos rumbos y consignas para la Sociología", que dictó en el Aula Máxima de la Facultad de Sociología de la Universidad Nacional de Colombia, el día 28 de octubre de 1965 señaló la necesidad de obtener una visión introspectiva de la cultura colombiana y latinoamericana, haciendo un mayor uso de la autonomía creadora. Según Fals Borda, la realidad latinoamericana en transformación merece ideas propias para explicarla y una metodología propia para describirla. Ello señala que hay conceptos muy aplicados a Europa que no corresponden a las realidades latinoamericanas, y como algunos ejemplos, los conceptos de burguesía, casta, élite, orden primitivo, frontera, república, modo de producción, feudalismo y otros que no son aplicables a las realidades americanas. Asimismo es importante conocer los desafíos que en los órdenes tecnológico y social representan los trópicos para la innovatividad humana. Lo anterior señala la necesidad de buscar los conceptos sociales, educativos, políticos y económicos aplicables a la realidad colombiana y latinoamericana. Estas ideas no significan un "Nacionalismo romántico" contra lo externo, sino un nacionalismo

19 FALS BORDA, Orlando. (1968): "Ciencia propia y colonialismo intelectual". Conferencia en la Facultad de Sociología de la Universidad Nacional de Colombia. Diciembre. Véase también el estudio "La Batalla por el pensamiento propio en Colombia", en Revista Nómadas de la Universidad Central.

\begin{tabular}{l|l} 
& Rhela. Vol. 12. Año 2009, pp. $13-41$
\end{tabular}


que mira hacia el futuro y que lleva, además, a una especie de "nacionalismo continental" dentro de la región latinoamericana, siguiendo sus lineamientos de la integración cultural, económica, social y política.

Ante el colonialismo científico se debe declarar la independencia intelectual, para estimular nuestros talentos y nuestra propia dignidad, combatiendo el colonialismo. Ello no significa que se rechacen los aportes culturales y científicos del mundo. La independencia intelectual significa que se deben conocer los adelantos científicos y su aplicación a nuestro medio para crear nuevas formas de trabajo y pensamiento que sean a su vez aportes a la comunidad universal de científicos. Significa poder tratar de igual a igual con colegas de otros países hoy más adelantados. Lo anterior señala que se deben conocer las nuevas corrientes intelectuales, las cuales deben ser recibidas sin dogmatismos o prejuicios. Saber discriminar lo que nos sirve y lo que nos es inútil, para el desarrollo de nuestra ciencia. Lo anterior indica que declarar la independencia intelectual es alcanzar dignidad y autoridad propias, dentro del mundo de la ciencia y las letras.

Según las ideas sociológicas y educativas del Dr. Orlando Fals Borda, Colombia y América Latina en general requieren de una ciencia comprometida con el desarrollo y con el cambio social profundo. "Necesitamos una ciencia social comprometida con los cambios y una investigación "telética" que sea proyectiva hacia el futuro." ${ }^{20}$

\section{El Manifiesto por la Autoestima en la Ciencia Colombiana}

Este manifiesto fue promulgado por los intelectuales Dr. Orlando Fals Borda por las Ciencias Sociales y el biólogo Dr. Luis Eduardo Mora Osejo por las Ciencias Naturales, el 4 de enero de 2001 y que fue publicado por Kaziyadu de Ediciones "desde abajo". Los dos grandes investigadores colombianos manifestaron su profunda preocupación por las distorsiones que surgen en la comprensión de nuestras realidades como país y como pueblo, cuando se analizan desde la perspectiva de otras realidades. Se refieren a las realidades de los países de la zona templada septentrional de la Tierra, donde las cada vez más sofisticadas innovaciones tecnológicas conforman el marco dentro del cual se desenvuelve, predominantemente, la sociedad de tales países. Estas realidades de los países europeos y norteamericanos se proyectaron en el informe de Desarrollo Humano para Colombia, publicado por el Programa de Naciones Unidas para el Desarrollo. Asimismo en los altos propósitos establecidos para los Sistemas Nacional de Ciencias y Tecnología, de Innovación y de Información, Seguimiento y Evaluación según leyes existentes.

Los dos intelectuales Orlando Fals Borda y Luis Eduardo Mora Osejo llamaron la atención a las instituciones colombianas que promueven la ciencia y la educación, entre ellas COLCIENCIAS, ICFES, Asociación Colombiana para el Avance de las

${ }^{20}$ FALS BORDA, Orlando. (1965): "Nuevos rumbos y consignas para la Sociología".

Conferencia en el aula máxima de la Facultad de Sociología, 28 de octubre. 
Ciencias, academias, universidades y en general, profesionales, gobernantes, empresarios y periodistas sobre los temas relacionados con la Ciencia colombiana. Según sus ideas, un marco científico debe aplicarse a las realidades de la sociedad en donde se realizan las investigaciones científicas. Ello señala que los paradigmas científicos europeos y norteamericanos, con su referente cultural en las zonas templadas donde se originaron, y en condiciones geográficas, históricas y humanas concretas, son aplicables a esas regiones y no son adaptados a nuestras realidades colombianas. Los modelos externos no se acoplan a la complejidad de Colombia con una naturaleza multidiversa, pluricultural y multiétnica y, además,

"cuando se adopta un modelo de Estado cuya normatividad no se inspira por lo general en esas realidades propias sino en las de Estados extranjeros, no nos sorprendamos de que muchas de nuestras leyes "se obedezcan pero no se cumplen". Ello contribuye a la desorganización y anomia generales, y conduce a una cierta esquizofrenia institucional con expresiones en el desorden socioeconómico y político del país, determinantes de las situaciones críticas que conocemos y sufrimos".

Los dos científicos señalan que es fundamental una metodología científica que sea aplicable a las realidades colombianas. Que no se busquen los modelos europeos y norteamericanos, que son los más propicios para sus realidades. Por ello, señalan que necesitamos Universidades que tengan por tarea prioritaria la consolidación en nuestro país de un ambiente cultural que propicie la creatividad a lo largo de todas las etapas de formación. Se requieren Universidades participativas, comprometidas con el bien común, en especial con las urgencias de las comunidades de base, que tomen en cuenta la formación de ciudadanos capaces de emitir juicios fundamentados en el conocimiento de las realidades sociales y naturales de nuestro país. Universidades que sean crisoles centrales de los mecanismos de creación, acumulación, enseñanza y difusión del conocimiento.

El manifiesto por la autonomía en la ciencia colombiana de los doctores Orlando Fals Borda y Luis Eduardo Mora Osejo, señaló que la ciencia colombiana no debe imitar en su totalidad los paradigmas de la ciencia propia para las realidades en Europa y Norteamérica, porque su aplicación no se ajusta a las realidades colombianas. "Por ello es importante el papel de las Universidades en la consolidación de la ciencia aplicada a las realidades colombianas y no a los paradigmas externos. "21

\section{El Dr. Orlando Fals Borda y el Método de Investigación Acción Participativa}

Este ilustre sociólogo y educador aplicó en sus investigaciones el método de la Investigación Acción Participativa (IAP). Según sus ideas, la metodología de la investigación-acción participante se aplica para ayudar a producir cambios radicales

${ }^{21}$ FALS BORDA, Orlando y MORA OSEJO, Luis Eduardo. (2001): "Manifiesto por la autoestima en la ciencia colombiana", en: Kaziyadu, Ediciones "desde abajo", 4 de enero. 
en la sociedad. Es un compromiso con la sociedad al hacer la investigación y entrar a los problemas para crear conciencia de cambio. "En los estudios históricos de la Costa Atlántica aplicó su método de investigación-acción, con la participación de las gentes de la región y el estudio de los archivos históricos y fuentes diversas para su estudio.”22

A nivel pedagógico, la "investigación acción” busca resolver un problema real y concreto. En el año 1946, el investigador Kart Lewin describió el proceso de "Action Research", indicando algunas de sus notas esenciales: contribución al cambio social, carácter participativo e impulso democrático. Se consideró importante la "decisión del grupo" y el "compromiso con la mejora". Este método se utilizó en la Década de los Cincuenta en los Estados Unidos, con mayor intensidad en la Década de los Setenta. En el Teachers College de la Universidad de Columbia en Nueva York, se estableció la Investigación-acción en el área educativa en el año 1953. "También se utilizó en el Reino Unido, Francia, Australia y otros países." ${ }^{23}$ En Colombia la introdujo el Dr. Orlando Fals Borda en sus investigaciones sociológicas y educativas.

Otros estudios realizados por el Doctor Orlando Fals Borda para explicar este método en Colombia, son los siguientes: "Investigación participativa" (Montevideo, Instituto del Hombre, (1986). "Reflexiones sobre la aplicación del método de estudioacción en Colombia" (1973); "El problema de cómo investigar la realidad para transformarla" (1979); "Ciencia propia y colonialismo intelectual" (1970); "Causa popular, ciencia popular" (1972); "El problema de la autonomía científica y cultural en Colombia" (1970). "La Batalla por el pensamiento propio en Colombia" (Revista Nómadas, Colombia). En relación con la educación, este método busca la unidad entre la teoría y la práctica, rompiendo esquemas como el de la división entre investigadores en educación y los que enseñan. Según la socióloga Dra. María Cristina Salazar, el método de la Investigación-Acción Participativa, IAP permite el desarrollo de un pensamiento creativo mediante el aprender haciendo, con la utilización de técnicas pedagógicas diversas, es decir, permite el paso de una educación dirigida por el maestro, a un enfoque centrado en el alumno. "De una transmisión de conocimientos por parte de "expertos" (investigadores) a una producción y elaboración de conocimientos en acciones compartidas por investigadores e investigados; o sea, por educadores y educandos." ${ }^{24}$

\section{El Congreso Mundial de Convergencia}

Con la coordinación del Dr. Orlando Fals Borda se realizó en Cartagena de Indias el Congreso Mundial de Convergencia Participativa en Conocimiento, Espacio y Tiempo, el cual se celebró entre el 31 de mayo al 5 de junio de 1997. Tuvo la colaboración del

\footnotetext{
22 SALAZAR María Cristina. (Coordinadora). (1992): La Investigación-Acción participativa. Inicios y desarrollos. Bogotá, Editorial Magisterio.

${ }^{23}$ BISQUERRA, Rafael. (2000): Métodos de Investigación Educativa. Guía práctica. Barcelona, Grupo Editorial Ceac, pp. 279-293.

${ }^{24}$ SALAZAR, María Cristina (Coordinadora). (1992): La investigación - Acción

Participativa. Inicios y desarrollos. Bogotá, Editorial Magisterio.
} 
Gobierno Nacional, el Ministerio de Educación, COLCIENCIAS, ICFES, UNESCO, cuatro Universidades Colombianas y otras instituciones. "En dicho Congreso se estudió el Método de investigación-acción participativa, con influencia directa en la educación colombiana." ${ }^{25}$

En el Congreso intervino el Ministro de Educación de Colombia, Dr. Jaime Niño Díez, quien señaló que la Investigación-Acción participativa es la metodología fundamental para los Proyectos Educativos institucionales para anclar la escuela en el corazón de las comunidades, alrededor de la investigación. Según el Ministro Niño Díez, la campaña "Desde la Escuela. La Paz de los Mil Días" que ha lanzado el Gobierno Nacional, encontró en la metodología de la Investigación-Acción Participativa un instrumento de singular importancia para construir la convivencia, a partir del impulso de miles de espacios donde se realicen cotidianamente y de manera creativa actos de paz.

\begin{abstract}
Que toda escuela, que todo colegio, que toda universidad, que todo centro educativo, constituyan nodos de una gran Red Nacional que haga posible la convergencia entre los colombianos. Que la escuela y la educación sean gestoras del tránsito de la vieja cultura de la guerra a la cultura de la paz, la convivencia y la solidaridad humana. ${ }^{26}$
\end{abstract}

Según el Dr. Orlando Fals Borda, el método de investigación acción participativa está relacionado con la epistemología holística, la cual se expresa en cuatro tipos de conocimiento que juegan entre sí: el vivencial o "experimental", el práctico, el proporsicional y el presentacional. Ello señala que hacer investigación participativa es aceptar que toda investigación sea interacción comunicante, en la que ocurre un proceso de diálogo de aprendizaje mutuo y de mutua confianza entre el investigador y el investigado. En este proceso se invalida la división tradicional entre conocimiento objeto y subjetivo; se afinan o complementan pautas normales de medición y análisis de la realidad; se equilibran los intereses teóricos del observador externo y de los actores locales que quieren transformar la práctica diaria, y se practica la interdisciplina. El resultado viene a ser tan calificado y respetable como el que se aduce para la investigación tradicional. Y el investigador como parte de de la realidad investigada se convierte en actor comprometido que debe a su vez analizarse y ser analizado.

Lo anterior llega a la definición del Método de Investigación Acción Participativa, teniendo en cuenta los planteamientos de los investigadores que asistieron al Congreso Mundial de Convergencia Participativa que se celebró en Cartagena en 1997, coordinado por el Dr. Orlando Fals Borda. Según los investigadores se llegó a la conclusión de que en la Investigación-Acción Participativa se combinan por lo menos dos elementos observables que la deslindan de otras formas de trabajo científico o investigativo. 1)

\footnotetext{
${ }^{25}$ FALS BORDA, Orlando (Coordinador). (1998): Participación popular. Retos del Futuro. Congreso Mundial de Convergencia en Investigación Participativa 97. Bogotá, ICFES, IEPRI, COLCIENCIAS.

${ }^{26}$ NIÑO DÍEZ, Jaime, Ministro de Educación de Colombia, "La investigación participativa y la educación. En: Participación popular. Retos del futuro, Op.cit, pp. 21-24.
} 
una estructura valorativa e ideológica con actitudes críticas relacionadas con el conocimiento y su utilización, el contexto social y patrones culturales en vía o en necesidad de mejoramiento y cambio; y 2) una batería de técnicas de encuestas multidisciplinarias combinables, derivadas de una sola lógica inmanente de investigación científica y de una epistemología holística o extensa.

La investigación-acción participativa se define como un método de estudio y acción que va al paso con una filosofía altruista de la vida para obtener resultados útiles y confiables en el mejoramiento de situaciones colectivas, sobre todo para las clases populares. Reclama que el investigador o la investigadora base sus observaciones en la convivencia con las comunidades, de las que también obtiene conocimientos válidos. Es inter o multidisciplinaria y aplicable a continuos que van de lo micro a lo macro de universos estudiados (de grupos a comunidades y sociedades grandes), pero siempre sin perder el compromiso existencial con la filosofía vital del cambio que lo caracteriza.

\section{La influencia de Paulo Freire y otros Pioneros de la Educación Social}

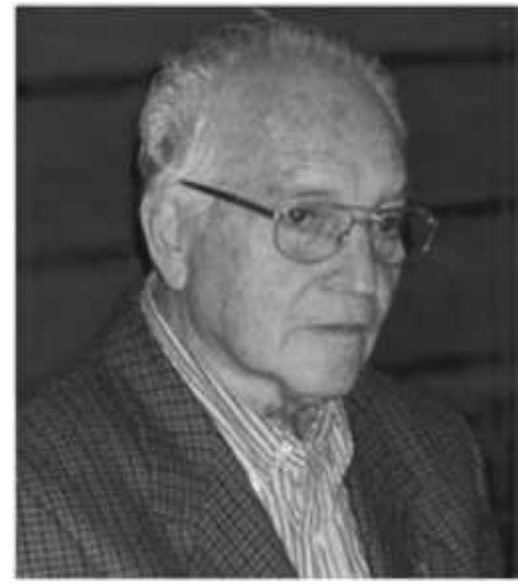

Dr. Orlando Fals Borda

En el Congreso Mundial de Convergencia se hizo un homenaje a los pioneros de la Educación social en el mundo. Entre ellos se dio realce a las ideas del pedagogo brasileño Paulo Freire, quien había sido un invitado especial al Congreso, pero falleció el 2 de mayo de 1997, pocos días antes del certamen. Este ilustre pedagogo, autor de las obras Pedagogía del oprimido, Educación para el cambio social, Pedagogía de la esperanza y muchas otras, buscó transformar la realidad social del Brasil por el camino de la alfabetización, en un mundo de pobreza e injusticia que necesita la socialización para transformar la sociedad. Se busca a través del "método Freire", que las gentes alcancen la conciencia de su realidad, a través del diálogo y la socialización, con la ayuda de unos y otros, para alcanzar la conciencia sobre la realidad que se vive y su camino de lucha para llegar a la justicia social. Debe ser una alfabetización a través de un proceso de concientización. Este método sigue los fundamentos de la educación activa, el diálogo, la crítica y la búsqueda permanente de creación de una conciencia sobre la realidad. El sociólogo y educador Orlando Fals Borda tuvo amistad personal con el pedagogo brasileño Paulo Freire y conoció su teoría educativa que influyó en algunos aspectos en sus ideas sobre el método de investigación-acción participativa.

Otro intelectual que recibió el homenaje en el Congreso Mundial de Convergencia fue el economista G.V.S. De Silva, quien se destacó por sus luchas por la autodeterminación, la justicia social y económica en los campos de la India en Maharashtra, durante los años Sesenta. Según sus ideas, el problema económico no se debe a la inestabilidad del crecimiento económico, sino a la falta de un crecimiento autogenerado que permita salir del estancamiento endémico. Con sus ideas se generó un movimiento de campesinos hindúes que se movilizaron, gracias al autodescubrimiento 
que hicieron de sus propias posibilidades intelectuales, políticas y económicas. Este movimiento tuvo repercusión en los lugares del mundo con problemas de injusticia social, relacionados con la distribución de la tierra y el poder político local. En Colombia influyó en la Asociación Nacional de Usuarios Campesinos (ANUC), uno de los más significativos movimientos campesinos del siglo XX.

Otros personajes que fueron homenajeados en el Congreso Mundial de Convergencia fueron: el educador y sociólogo inglés Andrew Pearse, fundador del Highlander Folk School, que se convirtió posteriormente en el llamado Highlander Research and Education Center en las montañas de Tennessee (USA); investigador social, especializado en programas para la educación de adultos. "El educador Myles Horton formador de activistas y educadores populares que trabajaron en los movimientos sindicales en el Sur de los Estados Unidos; una forma de educación para transformar la sociedad rural norteamericana. Asimismo, se hicieron homenajes a los educadores y sociólogos, el holandés Antón de Schutter, el brasileño Jao Bosco Pinto y al colombiano Antonio García, uno de los grandes ideólogos del cambio social en Colombia." ${ }^{27}$

\section{Planteamientos de la nueva Metodología}

La Metodología de la Investigación Acción Participativa que investigó y practicó el sociólogo y educador Dr. Orlando Fals Borda tiene aportes muy significativos para la educación popular de adultos y para toda la estructura de la educación nacional en una época de crisis y de cambios. En el Congreso de Cartagena se planteó el cambio de las formas y contenidos de la enseñanza; la aplicación de nuevas técnicas de la enseñanza, con una escuela activa y una educación nueva para transmitir la dinámica en la educación. Con este cambio se busca eliminar la metodología del maestro dictador y la rutina despedidora de escuelas, colegios y universidades.

Las nuevas tendencias llevan a recomendar las campañas de "aprendizaje acción", el "salto educativo" y "el maestro como investigador. Que la estructura académica y los pénsums escolares se preocupen más por los cambios en la sociedad a través de la educación. Que la educación en las escuelas, colegios y universidades se preocupen por el respeto a los derechos humanos y por la ciudadanía responsable; por defender la paz y la tolerancia en el manejo de las cuestiones públicas e interpersonales. "Que la educación fomente la creatividad de los educandos y la constante dinámica educativa a través de la escuela activa y participante. ${ }^{" 28}$ Con la nueva metodología, dice el Dr. Orlando Fals Borda, se debe estimular a los educadores para que tengan mayor decisión en las tareas de investigación participativa que se necesitan para conocer mejor la realidad escolar y comunitaria, para vincular y motivar a los estudiantes de todas las edades, hasta el punto de que lleguen a ser gestores de su propio aprendizaje, y para afirmar el papel de liderazgo y orientación colectiva que tienen los maestros.

27 FALS BORDA, Orlando. "Galería de los pioneros: Freire, De Silva, Pearse, Horton, Menciones”, en: Participación popular: Retos del futuro. Op.cit, pp. 29-40.

28 Orlando Fals Borda, “Fundamentos teóricos". En: Participación popular. Retos del Futuro op.cit. pp. 171-188.

Rhela. Vol. 12. Año 2009, pp. 13 - 41 
Una meta posible de la educación con la investigación-acción participativa es convertir el aula en un sistema articulado de comunicación, investigación y construcción del conocimiento entre todos los estamentos para llegar a una especie de Comunidad educativa integral. Se recomienda que los Maestros en sus escuelas y colegios formen grupos críticos de investigación activa que vayan progresivamente incorporando estudiantes y otros miembros de las escuelas a una labor colaborativa de auto-reflexión. Este nuevo método de investigación-acción participativa debe fortalecer la responsabilidad de los maestros para liderar con sus alumnos y con la comunidad de su entorno, la transformación de la sociedad colombiana a través de la educación.

Según las ideas del Dr. Orlando Fals Borda, la educación tiene un papel decisivo en el mejoramiento de la sociedad. Y esa función solamente es posible estimulando la investigación-acción en la enseñanza y en el aprendizaje. Debe ser una relación de Maestro-Alumno a través del conocimiento y la práctica que ofrece la investigación.

Con esta visión de la Educación, la Investigación-Acción participativa puede realizar un cambio en la educación colombiana, pues estimula la dinámica educativa, la educación nueva y la escuela activa con el "aprender haciendo". Estimula una educación integral centralizada más en el alumno que en el "Maestro dictador". Una educación basada en la investigación-acción en forma integral, con la participación de todos los estamentos de la institución: alumnos, profesores y padres de familia.

La Investigación Acción participativa se convierte en una fuerza educativa con liderazgo para los cambios necesarios en la comunidad. El maestro-investigador y sus alumnos se transforman en líderes de la comunidad, participando en la búsqueda de soluciones para los problemas de la sociedad de su entorno. Lo anterior señala que el adelanto de la educación para el progreso de los pueblos tiene un apoyo muy decisivo en la metodología de la investigación-acción participativa. Este fue el interés y la lucha del sociólogo y educador Dr. Orlando Fals Borda, que se convierte en su legado para la educación de las nuevas generaciones.

\section{La Educación Colombiana y su Desarrollo Histórico}

El educador, sociólogo e historiador, Dr. Orlando Fals Borda realizó una investigación sobre la situación de la educación en Colombia a través de su desarrollo histórico, desde la educación indígena y colonial hasta la segunda mitad del siglo XX. En su estudio La Educación en Colombia. Bases para su interpretación sociológica, que publicó en las Monografías sociológicas $\mathrm{N}^{\circ}$ 11, en la Facultad de Sociología de la Universidad Nacional de Colombia. Y en su estudio "La educación en el proceso revolucionario" que publicó en la obra Por ahí es la cosa, ensayos de Sociología e Historia Colombianas, que editó en "La Rosca" en 1972, reflexionó sobre la situación de la Educación colombiana en la segunda mitad del siglo XX y su evolución histórica desde los aborígenes. Su estudio corresponde a una de las conferencias que dictó en Barranquilla en abril de 1971, con otros cuatro expositores: Gonzalo Castillo Cárdenas, Víctor Daniel Bonilla, Carlos Duplat y Augusto Libreros. En estas conferencias se 
planteó la necesidad de una reorientación del proceso educativo, para comprometerlo con los problemas del pueblo colombiano y con la defensa de su patrimonio cultural. ${ }^{29}$

Según sus ideas, la educación puede considerarse desde dos puntos de vista: el técnico y el humanista. Según una definición técnica de educación, ésta es un conjunto de normas e instituciones destinadas a preservar y transmitir el conocimiento especializado dentro de una sociedad. Este enfoque destaca las relaciones personales en el marco educativo, en el salón de clase, en la escuela misma, principalmente en la relación entre maestro y estudiante, colocándolos en dos posiciones encontradas que van desde la pasividad hasta el conflicto. Perpetúa también la tradición de ver al profesor como un tirano, el que habla con autoridad que no puede discutirse.

Una definición humanista de educación, que es la más apropiada para su conocimiento y acción, según el Dr. Orlando Fals Borda, señala que ésta es una experiencia vital que comprende todos los procesos de asimilación mental y proyección del pensamiento, aquellos que permiten al hombre formarse una filosofía y una capacidad de acción social, sea como persona o como miembro de una colectividad. Este enfoque coloca la educación dentro de la sociedad, al descubrir la dimensión clasista en el proceso educativo; rompe el esquema del profesor tirano enfrentado al alumno pasivo y deja a aquél más bien frente a grupos sociales. El descubrimiento de la dimensión de clases lleva a la acción, es decir, a decidirse por diversas opciones que la realidad le va ofreciendo, con el fin de transformar revolucionariamente esa realidad. ${ }^{30}$

Según las ideas del Dr. Fals Borda, la educación va formando la sociedad colombiana en su estructura, y va justificando esta estructura ideológicamente, cimentando las formas de explotación interna anudándolas con las de dependencia externa. La educación en Colombia ha formado a los grupos dominantes en cada época. Estos grupos necesitaron de la educación para consolidar su poder económico, reforzar su situación social y racionalizar su actividad política.

Un estudio que hizo el Dr. Orlando Fals Borda sobre la Educación en la Historia de Colombia señala que hay tendencias o corrientes formativas de la política educativa. Entre ellas, distingue cuatro corrientes: la sacra, la cientifista, la democrática y la autonomista. En su obra La Educación en Colombia reflexiona sobre cada una de las corrientes educativas, iniciando con la educación chibcha en "los cucas" o seminarios en donde a niños cuidadosamente escogidos se les señalaba el rito de las ceremonias al sol, durante los cuales algunos de ellos mismos, los llamados moxas, eran inmolados. ${ }^{31}$

\footnotetext{
29 Véanse los estudios del Dr. Orlando Fals Borda: La Educación en Colombia. Bases para su interpretación sociológica. Bogotá, Universidad Nacional, Facultad de Sociología, 1962. Monografías Sociológicas $\mathrm{N}^{\circ} 11,37$ pág. Asimismo, su conferencia, "La educación en el proceso revolucionario", publicado en la obra Por ahi es la cosa, editado por La Rosca en Bogotá en 1972, pp. 17-34.

30 FALS BORDA, Orlando. "La educación en el proceso revolucionario", Op.cit. pp. 17-18.

31 FALS BORDA, Orlando. "La Educación en Colombia", Op.cit. pp. 5-6.
} 


\section{La Corriente Sacra}

A partir del siglo XVI, con la llegada de los españoles se inició en la educación colombiana la Corriente Sacra, con el predominio de la Iglesia Católica y especialmente las Comunidades religiosas en la educación del Nuevo Reino de Granada. Se organizaron dos tipos de escuelas para los indígenas locales: la doctrinera y la monástica. La primera se hacía alrededor de las "Doctrinas" en las encomiendas; y las escuelas monásticas se conformaron en las Comunidades religiosas con la ayuda de las autoridades civiles, para la formación de la nobleza indígena. Para los niños españoles y criollos surgieron las escuelas privadas en los conventos y los Colegios Mayores bajo el cuidado de las órdenes eclesiásticas. Ello indica que la Corona española dejó la tarea de la educación a la iniciativa privada de las Comunidades religiosas.

Los Dominicos y los Jesuitas se interesaron por organizar las primeras universidades en el Nuevo Reino de Granada. Los Jesuitas fundaron la Universidad Javeriana en 1622. Los Dominicos organizaron la Universidad Tomística en 1625, la única que estaba autorizada para conceder públicamente grados de teología y artes. Asimismo, se fundaron los Colegios Mayores Reales, con el ejemplo de los Colegios Mayores en España. El Colegio Real Mayor de San Bartolomé fue fundado en 1605; y el Colegio Real Mayor de Nuestra Señora del Rosario fue fundado en Santa Fe en 1653 por Fray Cristóbal de Torres. En estos dos Colegios Reales Mayores se formaron los hijos de noble linaje en el Nuevo Reino de Granada. Para la selección de estudiantes prevaleció el sistema de casta. En 1767 con la Expulsión de los Jesuitas, se suspendió la Universidad Javeriana y los Colegios bajo su dirección y organización. La educación sacra de la época colonial fue una educación para las clases privilegiadas (élites) que defendían las formas de dominación señorial, capitalista y mercantilista que ellas habían impuesto. Esta educación se constituyó como un monopolio eclesiástico.

Esta corriente sacra continuó en el siglo XIX, y se consolidó con la Constitución Nacional de 1886 y el Concordato de 1887, con la entrega de la educación a la Iglesia Católica para aplastar las tendencias ateas y liberales que habían aflorado con la Constitución Radical de 1863. Más adelante se suscribió el Tratado con el Vaticano, el Convenio de Misiones de 1953, que hace de la Iglesia un virtual gobernante de la mayor parte del territorio nacional. Sobre este hecho opina el Dr. Orlando Fals Borda:

Esta situación especial deja de lado al pueblo como entidad determinante, y permite que la empresa privada y otros grupos económicos intervengan más y más en la educación hasta el punto de llegar casi a dominarla. Siendo que este dominio no cambia la orientación elitista tradicional, es decir, que sigue sirviéndole a las minorías privilegiadas o adineradas, la política educativa resultante no refleja las verdaderas necesidades nacionales. Se ejecuta más como un negocio que como un servicio. Al mismo tiempo, decrece el control estatal sobre la educación. Por ejemplo, a la universidad privada asiste hoy el doble de la proporción de alumnos que tenía hace diez años, mientras que en las universidades oficiales esa proporción ha disminuido. ${ }^{32}$

${ }^{32}$ FALS BORDA, Orlando. “La educación en el proceso revolucionario”, op.cit. pp., 20-21. 
Así concluye el educador Orlando Fals Borda sobre la corriente sacra en la Historia de la Educación colombiana:

Los intereses sacros tradicionales convergen con los de la empresa privada y de grupos oligárquicos para mantener la educación como un privilegio de castas, y desconocer el derecho que tenemos todos los colombianos de educarnos $y$ de educar a nuestros hijos. ${ }^{33}$

\section{La Corriente cientificista}

es la segunda que analiza el ilustre educador costeño. Está relacionada con la Ilustración y el Racionalismo del siglo XVIII y la penetración de la ciencia en el Nuevo Reino de Granada. Su primer impacto en 1774 fue el plan de estudios de Moreno y Escandón, en el cual se propuso la enseñanza de las ciencias modernas como las matemáticas, la física, la astronomía y las ciencias naturales. Asimismo la participación de la Expedición Botánica con la influencia del Sabio José Celestino Mutis y del grupo de criollos rebeldes intelectuales que desafiaron el poder de España. La mayor parte de ellos pereció en los años de la Reconquista.

En la segunda mitad del siglo XIX surgió una nueva oligarquía que se interesó por la construcción de vías férreas y por la organización de una economía comercial, exportadora de nuestras materias primas. El énfasis fueron las ciencias exactas y físicas y la ingeniería. Se destacan las primeras escuelas de Ingeniería militar, la Comisión Corográfica y la fundación de la Universidad Nacional de Colombia. Surgieron las nuevas carreras de agronomía, ingeniería, medicina veterinaria, farmacia, odontología, arquitectura, administración pública y de empresas, química, psicología y otras.

Las nuevas carreras se dirigieron a consolidar el control de la burguesía comercial e industrial que se venía formando desde mediados del siglo XIX, para producir técnicos, expertos y doctores que sirvieran a la organización del Estado y de la empresa privada, con el fin de sostener las formas de explotación existentes, así en el campo como en la ciudad. Esta orientación educativa de servicio al "sistema" capitalista oligárquico se convirtió en el fondo del problema universitario de Colombia. ${ }^{34}$

\section{La Corriente Democratera}

Está relacionada con la aplicación del socialismo utópico y al interés del Liberalismo social por la educación popular y el alfabetismo. Se destacan las obras de los gobiernos de Santander y de José Hilario López que se interesaron por la educación popular y la construcción de escuelas. Mediante la Ley 2 de 1870, se dio importancia a la formación de los Maestros y a la creación de las Escuelas Normales, con la influencia de educadores alemanes. El Radicalismo alejó la influencia de la Iglesia en la educación $\mathrm{y}$ tuvo problemas en la enorme falta de escuelas, especialmente para la clase popular.

33 Ibídem, p. 21.

${ }^{34}$ Ibídem, pp. 21-23.

Rhela. Vol. 12. Año 2009, pp. 13 - 41 
Se rechaza el estudio hasta el $60 \%$ de los niños que aspiran a estudiar. Según el Informe Lebret, de los 100 alumnos que ingresan al primer año de primaria, sólo 12 llegan al sexto grado. Y en el mismo Informe se señala que de 2.500 niños que inician estudios en las escuelas colombianas, sólo uno llega a salir de la Universidad. La corriente democratera señaló la necesidad de la educación popular, pero ha mantenido la estructura elitista de nuestra sociedad. Favorece a los privilegiados y discrimina a los pobres, según su raza y posición social. ${ }^{35}$

\section{La Corriente autonomista}

Está vinculada a un proceso de dinamización popular, de un despertar de las clases trabajadoras, que ponen en entredicho las bases del sistema capitalista y dependiente que ha caracterizado a Colombia. Esta corriente busca la autenticidad y la independencia nacionales, sin perder la perspectiva y las vinculaciones internacionales que implica la lucha contra el imperialismo, cuya fuerza no reconoce fronteras; quiere romper esquemas importados de los países dominantes por ser anteojeras que impiden ver bien la realidad local y que, por el contrario, llevan a nuevas formas de dependencia; anhela abrir el compás de la educación para que llegue realmente al pueblo y le sirva en sus diarias necesidades.

Esta corriente autonomista surge de la clase popular frente a la burguesía dominante. Saca a la luz la riqueza cultural y técnica del pueblo y busca enraizarse en lo propio para recibir la vitalidad del movimiento revolucionario que implica un cambio social verdadero. Esta lucha autonomista comenzó a esbozarse en la primera subversión importante del siglo XX, entre 1920 y 1930. Varios grupos obreros, indígenas, campesinos y estudiantes se organizaron para luchar por la revolución popular colombiana, dando origen, en parte, a los nuevos partidos comunista y socialista que fueron sus abanderados. Recibió un nuevo impulso con el ejemplo de la Revolución Cubana en 1959 y las luchas de los campesinos colombianos con los obreros y los universitarios. Se luchó contra las limitaciones del gobierno del Frente Nacional y contra la inversión norteamericana en una época cuando se impuso la Guerra Fría del Departamento de Estado, que influyó también en los intereses exclusivos de los grupos dominantes tradicionales.

La corriente autonomista se manifiesta eminentemente revolucionaria, independentista y anti-imperialista, con las luchas de los usuarios campesinos y los universitarios. Lucha por la tierra, la reforma agraria integral y una educación popular con nuevos métodos y una nueva ideología. Considera el Dr. Fals Borda que es necesario la revaluación de "lo propio" en nuestras fuentes culturales: los conocimientos, técnicas, costumbres y creencias en las que se enraiza nuestra personalidad como colombianos. Es necesario rescatar lo autóctono y tratarlo con respeto y admiración, porque lo que es propio tiene una profunda razón de ser y de ello puede depender nuestra supervivencia. La tendencia a imitar lo externo es grave porque nos convertimos en seres sin

${ }^{35}$ Ibídem, pp. 23-25. 
personalidad; nos lleva a ser miembros de una sociedad de consumo que alimenta una maquinaria de propaganda internacional y nacional.

Señala el educador Fals Borda que los colombianos debemos crear una ciencia propia y técnicas pensando en nuestras realidades geográficas y humanas; la ciencia del trópico y de los tropicales, donde se halla toda una verdadera frontera científica. Esa ciencia y técnicas nuevas, adaptadas a nuestras necesidades y aspiraciones, deberían también revelar los mecanismos de la explotación y dominación existentes y las contradicciones de nuestra sociedad. ${ }^{36}$

En su estudio sobre “La Educación en Colombia" señala que la situación de la educación popular en Colombia es crítica, especialmente en el siglo XX y después de 1930 cuando los gobiernos han tratado de construir escuelas y de apresurar la preparación de maestros. Para su organización y consolidación que la educación necesita se han presentado numerosos obstáculos que es necesario precisar:

El peso de la tradición, la naturaleza de la estructura de clase, la interferencia de intereses creados, han dilatado la acción necesaria. Pero el número creciente de analfabetas en Colombia está demostrando ser una carga demasiado pesada, tan onerosa que ninguna nación moderna puede resignarse a soportarla. Ese analfabetismo, más el pobre contenido de lo que se enseña y la falta de un sentido ético en la educación, se encuentran en el fondo del fenómeno de "la violencia" y de la agitación rural. ${ }^{37}$

\section{CONCLUSIONES}

Es muy significativo señalar que el pensamiento y la acción del sociólogo, historiador, educador, político y profundo humanista Dr. Orlando Fals Borda, es de gran trascendencia para el análisis del pensamiento colombiano en la segunda mitad del siglo XX. Su interés por la creación de la Facultad de Sociología en la Universidad Nacional, para la formación de investigadores de los problemas sociales en Colombia con métodos científicos rigurosos. Sus estudios sociológicos y educativos señalaron los problemas fundamentales del pueblo colombiano en los mediados y segunda mitad del siglo XX: la violencia, la subversión, la vida rural, los problemas políticos, económicos, sociales, educativos y otros que manifestaron la crisis y la necesidad de cambios en las estructuras nacionales.

Para el estudio de los problemas socio-económicos y la psicología social de los campesinos boyacenses y de la Región Andina, sus aportes son de gran trascendencia, e indispensables para el conocimiento de este pueblo de transición entre el mundo tradicional, con raíces coloniales y el mundo actual de la modernización; un ejemplo para el conocimiento del pueblo colombiano y latinoamericano.

\footnotetext{
36 Ibídem, pp. 26-33.

37 FALS BORDA, Orlando. "La Educación en Colombia. Bases para su interpretación sociológica”, p. 30 .
} 
A nivel mundial transmitió su método de Investigación-acción participativa, IAP, que es fundamental para el conocimiento y la participación en los problemas del pueblo colombiano y latinoamericano. Esta metodología de la investigación-acción participante se aplica para ayudar a producir cambios radicales en la sociedad. En los últimos años, su mayor interés fue el ordenamiento territorial para Colombia, como instrumento fundamental para la administración de los recursos, del poder y los conflictos. Su ejemplo como profundo investigador de la realidad colombiana, con métodos científicas rigurosos que plasmó en sus numerosas obras, estudios y ponencias publicadas en las principales revistas de Colombia y el Mundo, es digno de estudio profundo y de imitación para las nuevas generaciones colombianas del siglo XXI.

\section{FUENTES}

\section{OBRAS DEL Dr. ORLANDO FALS BORDA}

FALS BORDA, Orlando. (1959): La teoría y la realidad del cambio socio-cultural en un sistema social rural. Bogotá, Facultad de Sociología, Monografía № 2. . (1961): Acción comunal en una vereda colombiana. Bogotá. Facultad de Sociología. Universidad Nacional. Monografía $\mathrm{N}^{\circ} 4$.

. (1961): Campesinos de los Andes. Estudio sociológico de Saucío.

Bogotá, Universidad Nacional, Facultad de Sociología, Monografías sociológicas $\mathrm{N}^{\circ} 7$. Editorial Iqueima.

. (1962): La educación en Colombia. Bogotá, Facultad de Sociología. . (1968): Revoluciones inconclusas en América Latina 1809-1968. México, Siglo XXI Editores.

. (1968): Subversión y cambio social. Bogotá, Tercer Mundo. Colección

"Dedo en la Herida", $\mathrm{N}^{\circ} 29$.

. (1975): Historia de la cuestión agraria en Colombia. Bogotá, Punta

de Lanza.

(1976): Capitalismo, hacienda y poblamiento en la Costa Atlántica.

Bogotá. Punta de Lanza.

. (1979): Historia Doble de la Costa. Mompox y Loba. Bogotá, Carlos

Valencia Editores. Tomo I. El Presidente Nieto (1981), Tomo II; Resistencia en el San Jorge (1984), Tomo III. Retorno a la tierra. (1986), Tomo IV. Edición especial de la Vicepresidencia de la República. Bogotá. Ancora Editores (4 tomos).

. (1986): El problema de cómo investigar la realidad, para transformarla. Bogotá. Tercer Mundo.

. (1996): Región e Historia: elementos sobre ordenamiento y equilibrio regional en Colombia. Bogotá, TM Editores.

. (2000): Acción y espacio. Autonomía en la Nueva República. Bogotá.

Instituto de Estudios Políticos. Universidad Nacional. Tercer Mundo Editores.

. (2006): El Hombre y la Tierra en Boyacá. Bases sociológicas e

históricas para una Reforma Agraria. Tunja. UPTC. Universidad Pedagógica y

Tecnológica de Colombia. 


\section{SELECIÓN BIBLIOGRÁFICA}

GUZMÁN CAMPOS, Germán (Monseñor), FALS BORDA, Orlando y UMAÑA LUNA, Eduardo. (1962): La Violencia en Colombia. Estudio de un proceso social. Bogotá, Ediciones Tercer Mundo. Facultad de Sociología Universidad Nacional. Monografías sociológicas, $N^{\circ} 12$. Bogotá, Editorial Taurus y Alfaguara.

SALAZAR María Cristina, (Coordinadora), (1992): La Investigación-Acción participativa. Inicios y desarrollos. Bogotá, Editorial Magisterio.

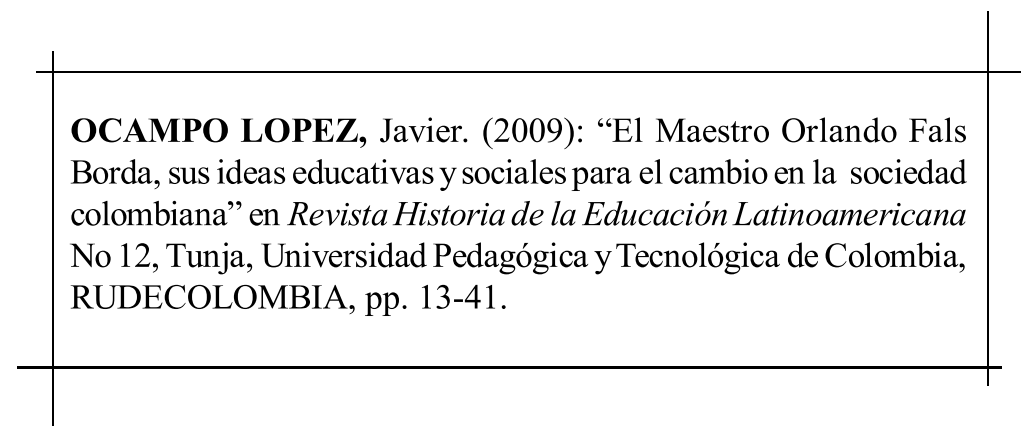

Rhela. Vol. 12. Año 2009, pp. 13 - 41 